\title{
Bradford's zone to Law Subject Publications Published in Yuridika Journal: A Citation Study
}

\author{
Esti Putri Anugrah ${ }^{1}$, Deaby Claudia M, Ario Adi Prakoso, Catharina \\ Labore Tatiek A, Ahdie Anwary, Rom Ubaidillah Muhammad, I Ketut \\ Gunadi Adi Guna \\ Sekolah Pascasarjana Universitas Gadjah Mada Yogyakartaa
}

\begin{abstract}
Abstrak
Jurnal merupakan salah satu publikasi ilmiah yang tidak diragukan lagi kredibitas dan kualitas informasi yang ada di dalamnya, karena terdapat proses editorial yang panjang sebelum informasi tersebut diterbitkan. Namun ada beberapa jurnal yang kurang berkualitas. Untuk mengukur kualitas suatu publikasi ilmiah jurnal dapat dilakukan dengan menghitung produktivitas jurnal tersebut, perihitungan tersebut menggunakan kaidah Bradford. Artikel ini memberikan ulasan tentang produktivitas jurnal Yuridika Fakultas hukum Universitas Airlangga. Metode penelitian yang digunakan dalam penelitian ini yaitu metode kuantitatif dengan perhitungan menggunakan kaidah Bradford. Berdasarkan perhitungan yang telah dilakukan, hasil perhitungan menunjukkan bahwa pola distribusi jurnal Yurdika dalam kurun waktu tiga tahun yaitu 2015-2017 dengan total artikel sebanyak 254 dan terdapat 131 nama jurnal sesuai dengan pola distribusi bradford $1: n: n^{2}$. Pembagian pola distribusi tersebut yaitu sebanyak 4 jurnal mencakup 92 artikel, sebanyak 22 jurnal mencakup 57 artikel, dan sebanyak 105 jurnal mencakup 105 artikel. Dari perhitungan menggunakan kaidah Bradford ini dapat menunjukkan bahwa Jurnal Yuridika merupakan salah satu literatur dalam bidang subjek hukum yang berpengaruh dan sebagai alat komunikasi ilmiah untuk mempublikasikan hasil penelitian.
\end{abstract}

Kata kunci: Hukum Bradford, produktivitas jurnal, komunikasi ilmiah.

\footnotetext{
${ }^{1}$ Korespondensi: Esti Putri Anugrah, Sekolah Pascasarjana Universitas Gadjah Mada, Jalan Teknika Utara Sleman Yogyakarta, E-mail: estiputri48@gmail.com
} 


\section{Pendahuluan}

Jurnal merupakan salah satu publikasi ilmiah yang tidak diragukan lagi kredibitas dan kualitas informasi yang ada di dalamnya. Selain tesis, buku atau laporan penelitian, publikasi ilmiah jurnal ini banyak sekali yang menggunakannya, terlebih lagi untuk kalangan para peneliti dan dosen, jurnal digunakan sebagai sumber informasi utamanya (Jayanti, 2017; Imtihana, 2012; Cahyono, 2011). Di antara berbagai sumber ilmiah yang ada, jurnal dianggap sebagai sumber informasi yang konten informasi di dalamnya memuat kebaharuan ilmu pengetahuan yang tinggi jika dibandingkan sumber informasi lainnya, mencakup informasi dan ide baru yang nantinya bisa diteliti kembali dengan objek penelitian yang berbeda. Di dalam jurnal dapat mencakup informasi mendalam tentang pemikiran mikro, perbandingan subjek, studi mendalam tentang subjek atau perkembangan baru dalam suatu subjek, dan masih banyak lagi yang lainnya (Wardikar, 2013)

Bagaimana tidak seperti itu, sebelum informasi dalam bentuk artikel dipublikasikan harus melewati proses editorial yang sangat panjang untuk mendapatkan informasi yang sangat berkualitas untuk dijadikan rujukan (Mamdapur, 2014). Namun ditemukan juga ada beberapa publikasi ilmiah jurnal yang dinilai kurang berkualitas dalam mempublikasikan suatu artikel. Untuk mengukur kualitas suatu publikasi ilmiah jurnal dapat dilakukan dengan menghitung produktivitas jurnal tersebut, perihitungan tersebut menggunakan kajian bibliometrika. Terdapat banyak kaidah atau hukum dalam kajian bibliometrika, yang berfokus pada perhitungan produktivitas jurnal yaitu kaidah bradford. Perhitungan produktivitas jurnal perlu dilakukan untuk mengetahui kualitas suatu jurnal dalam bidang tertentu. Tujuan dari artikel ini yaitu untuk menghitung produktivitas jurnal dengan subjek hukum dengan waktu yang telah ditentukan. 


\section{Tinjauan Literatur}

\section{Kaidah Bradford}

Kaidah Bradford disampaikan oleh Samuel Clement Bradford seorang pustakawan pada Science Museum Library London (1935-1948). Kaidah ini merupakan salah satu kaidah dalam kajian bibliometrika. Terdapat banyak bidang kajian bobliometrika, seperti contohnya kaidah zifp untuk menghitung produktivitas kata yang digunakan sebagai kata kunci suatu dokumen; kaidah lotka digunakan untuk menghitung produktivitas pengaran suatu karya buku, karya akhir mahasiswa atau jurnal. Sedangkan kaidah Bradford digunakan untuk mengalisis produktivitas suatu set jurnal dalam subjek bidang tertentu dengan kurun waktu yang telah ditentukan. Kaidah distribusi atau penyebaran Bradford mengindikasikan bahwa banyaknya artikel yang tersebar di dalam jurnal yang lebih sedikit dan sejumlah besar jurnal memiliki artikel yang lebih sedikit secara proporsional. Distribusi artikel dapat berbeda dalam beberapa perkiraan rasio yang dinyatakan melalui persamaan berikut ini

\section{1: $\mathrm{n}: \mathrm{n}^{2}$}

Bradford telah menyiapkan daftar jurnal yang digunakan dalam bibliografi pada subjek Geofisika Terapan dan Pelumasan kemudian menyusunnya dalam urutan menurun. Dia mengidentifikasi tiga kelompok jurnal yang diberi peringkat berdasarkan produktivitas dari jurnal. Kelompok/zona pertama memiliki jumlah jurnal paling kecil namun sangat produktif yang disebut zona inti; kelompok/zona kedua memiliki jurnal yang cukup produktif dalam jumlah relatif besar; kelompok ketiga disebut zona produktif rendah yang memiliki sejumlah besar jurnal produktif yang rendah (Birger \& Jeppe, 2005).

Penerapan kaidah Bradford yang dilakukan oleh peneliti menggunakan kutipan jurnal ataupun disertasi dari subyek yang telah ditentukan. Perhitungan produktivitas jurnal yang dilakukan oleh Sudhier (2010) menerapkan kaidah Bradford pada literatur fisika yang digunakan oleh 
Indian Institute of Science untuk tesis doktor mereka. Hasil penelitian mengungkapkan bahwa kaidah tersebut cocok untuk proses kumpulan data. Demikian pula, penelitian yang dilakukan oleh Banateppanvar, Birdar, dan Kannappanavar (2013) yang menerapkan kaidah Bradford ke jurnal Botani yang dikutip oleh mahasiswa doktoral Universitas Kuvempu India dalam tesis. Hasil penelitian menemukan pola penggunaan jurnal para peneliti. Penerapan kaidah Bradford juga ditemukan sesuai dengan studi The Electronic Library Journal selama tahun 2003-2009 (Jena, Swain, \& Sahu, 2012). Namun hal yang sebaliknya terjadi, penghitungan produktivitas jurnal dengan kaidah Bradford juga dilakukan oleh Zafrunnisha (2012) pada kutipan dari tesis doktoral psikologi. Peneliti mengidentifikasi zona Bradford dan produktivitas jurnal yang dikutip dalam tesis doktor dan menemukan bahwa penyebaran judul jurnal dalam psikologi tidak memenuhi kaidah Bradford. Berdasarkan pemaparan penelitian terdahulu bahwa penerapan kaidah Bradford pada perhitungan produktivitas jurnal tidaklah selamanya sesuai, ada kalanya tidak ada kesesuain antara data jurnal dan kaidah bradford itu sendiri.

\section{Metode Penelitian}

Metode yang digunakan yaitu metode dengan pendekatan kuantitatif dengan menghitung produktivitas jurnal yang telah ditentukkan. Jurnal yang dijadikan sebagai objek penelitian adalah Jurnal Yuridika yang diterbitkan oleh Fakultas Hukum Universitas Airlangga dalam kurun waktu tiga tahun yaitu tahun 2015-2017. Jurnal Yuridika merupakan salah satu jurnal dalam subjek bidang hukum, yang diterbitkan oleh Fakultas Hukum Universitas Airlangga, sudah terakreditasi nasional pada tahun 2017. Jurnal Yuridika ini mulai terbit pada tahun 1976 dalam versi cetak, dan sekarang ini sudah beralih menggunakan versi Open Journal System (OJS), terbit 3 kali pada setiap tahunnya (Pada bulan Januari, Mei dan Desember) dengan jumlah artikel yang diterbitkan sebanyak 8 artikel pada masing-masing edisi. Jadi pada analisis sitasi ini artikel yang digunakan sebagai data untuk analisis sitasi sebanyak 72 artikel ( $8 \times 3$ edisi per tahunnya $\mathrm{x} 3$ tahun $=72$ ). Berikut ini merupakan tabel rincian artikel yang diterbitkan pada setiap tahunnya. 
Bradford's zone to Law Subject Publications Published in Yuridika Journal:

A Citation Study

\begin{tabular}{ccccc}
\hline Tahun & Volume & Nomor & Total Publikasi & $\mathbf{\%}$ \\
\hline 2015 & 30 & 1 & 8 & 11,11 \\
\hline 2015 & 30 & 2 & 8 & 11,11 \\
\hline 2015 & 30 & 3 & 8 & 11,11 \\
\hline 2016 & 31 & 1 & 8 & 11,11 \\
\hline 2016 & 31 & 2 & 8 & 11,11 \\
\hline 2016 & 31 & 3 & 8 & 11,11 \\
\hline 2017 & 32 & 1 & 8 & 11,11 \\
\hline 2017 & 32 & 2 & 8 & 11,11 \\
\hline 2017 & 32 & 3 & 8 & 11,11 \\
\hline & Total & & 72 & 100 \\
\hline
\end{tabular}

Berdasarkan hasil perhitungan yang didapatkan, pada Jurnal Yuridika dalam kurun waktu tahun 2015-2017, dari 72 artikel yang telah dipilih sebagai objek penelitian terdapat 1137 referensi dari berbagai jenis sumber informasi, yang selanjutnya akan lebih berfokus pada sumber informasi jurnal saja. Dari sumber informasi semua jurnal, terdapat sebanyak 131 nama jurnal yang berbeda dan 254 sitasi pada artikel. Dari 131 jurnal dan 254 sitasi pada artikel tersebut, kemudian dilakukan perhitungan untuk mendapatkan pembagian 3 zona jurnal dengan menggunakan bantuan kaidah Bradford.

\begin{tabular}{clr}
\hline No & \multicolumn{1}{c}{ Jenis Sumber Informasi } & f \\
\hline 1 & Buku & 713 \\
\hline 2 & Jurnal & 254 \\
\hline 3 & Undang-undang & 104 \\
\hline 4 & Laman Website & 36 \\
\hline 5 & Disertasi & 6 \\
\hline 6 & Tesis & 4 \\
\hline 7 & Skripsi & 5 \\
\hline 8 & Prosiding & 5 \\
\hline 9 & Keputusan Perusahaan & 6 \\
\hline 10 & Laporan Penelitian & 2 \\
\hline 11 & Kamus & 1 \\
\hline 12 & Karya Ilmiah & 1 \\
\hline & Jumlah & 1137 \\
\hline & $\quad$
\end{tabular}




\section{Hasil dan Analisis}

Produktivitas Jurnal Yuridika pada tahun 2015-2017 berjumlah 131 nama jurnal. Nama jurnal yang paling sering digunakan sebagai referensi atau disitasi dari 72 artikel dalam rentang waktu 2015-2017 yaitu Yuridika dengan frekuensi sebanyak 68 kali, Jurnal Yuridika ini merupakan jurnal yang digunakan sebagai data penelitian kali ini, sehingga memang sudah sewajarnya ketika nama Jurnal Yuridika mendapatkan jumlah sitasi jurnal yang banyak. Yang kedua yaitu Jurnal Konstitusi dengan frekuensi sebanyak 12 kali. Frekuensi sebanyak 6 kali pada Jurnal Penelitian dan The Yale Law Journal. Terdapat 2 jurnal dengan frekuensi sebanyak 5 kali yaitu Jurnal Perspektif dan Jurnal Mimbar Hukum. Berikut ini tabel yang memuat namanama jurnal beserta frekuensinya yang terdapat dalam Jurnal Yuridika tahun 2015-2017.

\begin{tabular}{clr}
\hline No & Nama Jurnal & f \\
\hline 1 & Yuridika & 68 \\
\hline 2 & Jurnal Konstitusi & 12 \\
\hline 3 & Jurnal Penelitian & 6 \\
\hline 4 & The Yale Law Journal & 6 \\
\hline 5 & Perspektif & 5 \\
\hline 6 & Mimbar Hukum & 5 \\
\hline 7 & RECIEL & 4 \\
\hline 8 & Jurnal Dinamika Hukum & 3 \\
\hline 9 & Jurnal Hukum Ius Quia Isutium & 3 \\
\hline 10 & Jurnal Ilmu Hukum & 3 \\
\hline 11 & Jurnal Pro Justitia & 3 \\
\hline 12 & Jurnal Yudisial & 3 \\
\hline 13 & Dinamika Sosbud. & 2 \\
\hline 14 & European Environmental Law Review. & 2 \\
\hline 15 & Journal of International Law & 2 \\
\hline 16 & Journal Of Questiones Document Examination. & 2 \\
\hline 17 & Jurnal Equality & 2 \\
\hline
\end{tabular}




\begin{tabular}{|c|c|c|}
\hline No & Nama Jurnal & f \\
\hline 18 & Jurnal Hukum Bisnis & 2 \\
\hline 19 & Jurnal Hukum. & 2 \\
\hline 20 & Jurnal Ilmiah Hukum & 2 \\
\hline 21 & Jurnal Minuta. & 2 \\
\hline 22 & Jurnal Yustisia & 2 \\
\hline 23 & Majalah Kedokteran Indonesia & 2 \\
\hline 24 & Musawa & 2 \\
\hline 25 & Perspektif Hukum & 2 \\
\hline 26 & Wacana Paramarta & 2 \\
\hline 27 & AGORA International Journal of Juridical Sciences & 1 \\
\hline 28 & Al-Adl. & 1 \\
\hline 29 & Algoritma. & 1 \\
\hline 30 & Al-Risalah Jurnal Hukum Keluarga Islam. & 1 \\
\hline 31 & American Bankruptcy Law Journal. & 1 \\
\hline 32 & American Journal of International Law & 1 \\
\hline 33 & American University International Law Review & 1 \\
\hline 34 & Annual Survey of International and Comparative Law & 1 \\
\hline 35 & Anthos Academic Journal. & 1 \\
\hline 36 & Arena Hukum & 1 \\
\hline 37 & Austrian Review of International and European Law Online & 1 \\
\hline 38 & Bambang Poerdyatmono & 1 \\
\hline 39 & Barkeley Journal of International Law. & 1 \\
\hline 40 & Boston University International Law Journal & 1 \\
\hline 41 & Brooklyn Journal of Corporate, Financial, \& Commercial Law. & 1 \\
\hline 42 & Brooklyn Journal of International Law & 1 \\
\hline 43 & Buletin Ekonomi Moneter dan Perbankan & 1 \\
\hline 44 & Chinese Journal of International Law. & 1 \\
\hline 45 & Common Market Law Review. & 1 \\
\hline 46 & Cornell Law Quarterly. & 1 \\
\hline 47 & Dinamika Hukum. & 1 \\
\hline 48 & Diplomasi & 1 \\
\hline 49 & Drake Journal of Agricultural Law. & 1 \\
\hline 50 & Duke Law Journal & 1 \\
\hline
\end{tabular}




\begin{tabular}{|c|c|c|}
\hline No & Nama Jurnal & f \\
\hline 51 & Elder Law Journal. & 1 \\
\hline 52 & Employee Relations Law Journal & 1 \\
\hline 53 & Ensuring Access to the Outcomes of Community Resource Projects' & 1 \\
\hline 54 & Fordham International Law Journal & 1 \\
\hline 55 & Hague Justice Journal & 1 \\
\hline 56 & HAM. & 1 \\
\hline 57 & Harper \& Row Publishers & 1 \\
\hline 58 & Hofstra Law Review. & 1 \\
\hline 59 & Hukum dan Pembangunan & 1 \\
\hline 60 & Hukum. & 1 \\
\hline 61 & IELTR N1 & 1 \\
\hline 62 & Ilmu Hukum Legal Opinion. & 1 \\
\hline 63 & ILSA Journal of International and Comparative Law & 1 \\
\hline 64 & Independent. & 1 \\
\hline 65 & Indonesian Journal of Environmental Law & 1 \\
\hline 66 & Info Singkat Hubungan Internasional & 1 \\
\hline 67 & Insolvency Law Journal & 1 \\
\hline 68 & International and Comparative Law Quarterly. & 1 \\
\hline 69 & International Business \& Economics research Journal & 1 \\
\hline 70 & International Insolvency Review & 1 \\
\hline 71 & International Journal of Criminology & 1 \\
\hline 72 & International Journals of Discrimination and The Law & 1 \\
\hline 73 & International Labour Review. & 1 \\
\hline 74 & International Legal Materials & 1 \\
\hline 75 & Journal Hasanuddin Law Review. & 1 \\
\hline 76 & Journal of Economic International Law & 1 \\
\hline 77 & Journal of Economic Perspective & 1 \\
\hline 78 & Journal of International Banking Law and Regulation. & 1 \\
\hline 79 & Journal of International Economic Law & 1 \\
\hline 80 & Journal of Islamic Law & 1 \\
\hline 81 & Journal of Korean Law. & 1 \\
\hline 82 & Journal of Legal Technology Risk Management & 1 \\
\hline
\end{tabular}




\begin{tabular}{llr}
\hline No & \multicolumn{1}{c}{ Nama Jurnal } & f \\
\hline 83 & Journal of Nusantara Studies & 1 \\
\hline 84 & Journal of Public Economics & 1 \\
\hline 85 & Journals of policy Analysis and Management & 1 \\
\hline 86 & Jurnal Adil & 1 \\
\hline 87 & Jurnal Advokasi & 1 \\
\hline 88 & Jurnal Business Review. & 1 \\
\hline 89 & Jurnal Delicti & 1 \\
\hline 90 & Jurnal Ekonomi \& Kebijakan Publik. & 1 \\
\hline 91 & Jurnal FISIP UMRAH & 1 \\
\hline 92 & Jurnal Hukum Ekonomi & 1 \\
\hline 93 & Jurnal Ilmiah Fakultas Hukum Universitas Pattimura Ambon 'SASI & 1 \\
\hline 94 & Jurnal Keadilan & 1 \\
\hline 95 & Jurnal on the Rule of Law. & 1 \\
\hline 96 & Jurnal Opinio Juris & 1 \\
\hline 97 & Jurnal Rechsvinding & 1 \\
\hline 98 & Jurnal Repertorium. & 1 \\
\hline 99 & Jurnal Ultimatum & 1 \\
\hline 100 & Jurnal Wawasan Hukum & 1 \\
\hline 101 & Kluwer Law International-the Netherland & 1 \\
\hline 102 & Kritike Journal of Philosophy. & 1 \\
\hline 103 & Magister Hukum Udayana. & 1 \\
\hline 104 & Majalah Masyarakat ASEAN - Media Publikasi Direktorat Kerjasama & 1 \\
\hline & ASEAN Kementerian Luar Negeri RI. & 1 \\
\hline 105 & Majalah Renvoi & 1 \\
\hline 106 & North Carolina Journal of International Law and Commercial \\
\hline 107 & Regulation. & 1 \\
\hline 108 & Oxford Journal & 1 \\
\hline 109 & Pandecta & 1 \\
\hline 110 & Panorama Hukum. & 1 \\
\hline 111 & Peradaban & \\
\hline 112 & Personality and Sociology Psichology Bulletin & 1 \\
\hline 113 & Public Policy and Administration Journal. & \\
\hline & & 1 \\
\hline
\end{tabular}




\begin{tabular}{llr}
\hline No & \multicolumn{1}{c}{ Nama Jurnal } & f \\
\hline 114 Risalah Hukum Fakultas Hukum Ummul. & 1 \\
\hline 115 Singapore Academy of Law Journal. & 1 \\
\hline 116 & Singapore of Academy Law Journal & 1 \\
\hline 117 Stanford Law Review & 1 \\
\hline 118 & Texas International Law Journal & 1 \\
\hline 119 & Texas Law Review & 1 \\
\hline 120 & The Australasian Journal of Construction Economics and Building & 1 \\
\hline 121 & The Dovenschmidt Quarterly & 1 \\
\hline 122 & The Infomation Society & 1 \\
\hline 123 & The International and Comparative Law Quarterly & 1 \\
\hline 124 & Tulane Maritime Law Journal. & 1 \\
\hline 125 & Undergraduate Research Journal for Human Sciences. & 1 \\
\hline 126 & UNSW Law Journal & 1 \\
\hline 127 & USU Law Jurnal. & 1 \\
\hline 128 Washington Law Review & 1 \\
\hline 129 Wawasan Hukum & 1 \\
\hline 130 & Widener Law Symposium Journal & 1 \\
\hline 131 & Widya &
\end{tabular}

Dari tabel di atas, dapat diringkan menjadi tabel seperti di bawah ini, karena dapat mempermudah proses penghitungan produktivitas jurnal.

\begin{tabular}{ccc}
\hline No & Jurnal & Artikel \\
\hline 1 & 1 & 68 \\
\hline 2 & 1 & 12 \\
\hline 3 & 2 & 6 \\
\hline 4 & 2 & 5 \\
\hline 5 & 1 & 4 \\
\hline 6 & 5 & 3 \\
\hline 7 & 14 & 2 \\
\hline 8 & 105 & 1 \\
\hline
\end{tabular}


Tabel di atas kemudian dilengkapi dengan perhitungan komulatif jurnal dan artikel seperti tabel yang terdapat di bawah ini,

\begin{tabular}{ccccccc}
\hline No & Jurnal & Artikel & $\begin{array}{c}\text { Jumlah } \\
\text { Kumulatif } \\
\text { Jurnal }\end{array}$ & $\begin{array}{c}\text { Jumlah } \\
\text { Kumulatif } \\
\text { Artikel }\end{array}$ & $\begin{array}{c}\text { Ln } \\
\text { Komulatif } \\
\text { Jurnal }\end{array}$ & $\begin{array}{c}\text { Prosentase } \\
\text { Kumulatif } \\
\text { Artikel }\end{array}$ \\
\hline 1 & 1 & 68 & 1 & 68 & 0 & 26,77 \\
\hline 2 & 1 & 12 & 2 & 80 & 0,69 & 31,50 \\
\hline 3 & 2 & 6 & 4 & 92 & 1,39 & 36,22 \\
\hline 4 & 2 & 5 & 6 & 102 & 1,79 & 40,15 \\
\hline 5 & 1 & 4 & 7 & 106 & 1,95 & 41,73 \\
\hline 6 & 5 & 3 & 12 & 121 & 2,48 & 47,64 \\
\hline 7 & 14 & 2 & 26 & 149 & 3,26 & 58,66 \\
\hline 8 & 105 & 1 & 131 & 254 & 4,88 & 100 \\
\hline & 131 & 254 & & & & \\
\hline
\end{tabular}

Untuk menentukan 3 zona Jurnal Yuridika dalam kurun waktu 3 tahun yaitu tahun 2015-2017, dilakukan dengan proses penghitungan pengganda bradford dengan menggunakan persamaan matematika seperti berikut ini.

$$
\mathrm{k}=\left(\mathrm{e}^{\gamma} \mathrm{Y}_{\mathrm{m}}\right)^{1 / \mathrm{p}}
$$

$\gamma=0,5772$ (Euler's number)

e $=2,718$ (constant)

$\mathrm{e}^{\gamma}=1,781$

$\mathrm{p}=3$ zona

$\mathrm{Y}_{\mathrm{m}}=$ artikel dengan frekuensi terbanyak (68)

Maka k $=(1,781.68)^{1 / 3}$

$$
=4,87
$$

Kemudian mencari $\mathrm{r}_{0}, \mathrm{r}_{0}$ merupakan nomer jurnal di zona pertama

$$
\begin{aligned}
\mathrm{r}_{0} & =\mathrm{T}(\mathrm{k}-1) /\left(\mathrm{k}^{\mathrm{p}}-1\right), \text { di mana } \mathrm{T}=\text { total komulatif jurnal. } \\
& =131(4,87-1) /\left(4,87^{3}-1\right) \\
& =506,97 / 114,5
\end{aligned}
$$




$$
\begin{aligned}
& =4,42 \\
& =4
\end{aligned}
$$

Maka nilai jurnal pada masing-masing zona, dapat dihitung sebagai berikut

$$
\begin{aligned}
& r_{0}=r_{0} \times 1=4,42=4 \\
& r_{1}=r_{0} \times k=4,42 \times 4,87=21,52=22 \\
& r_{2}=r_{0} \times k^{2}=4,42 \times 4,87^{2}=104,84=105
\end{aligned}
$$

Berikut ini tabel pembagian zona jurnal dan artikel

\begin{tabular}{ccccc}
\hline Zona & Artikel & Jurnal & Perbandingan & $\begin{array}{c}\text { Pengganda } \\
\text { Bradford }\end{array}$ \\
\hline Zona 1 & 92 & 4 & - & - \\
\hline Zona 2 & 57 & 22 & 5,5 & 5,5 \\
\hline Zona 3 & 105 & 105 & 26,25 & 4,77 \\
\hline Jumlah & 254 & 131 & & 5,14 \\
\hline
\end{tabular}

Dari perhitungan di atas, di dapatkan pengganda Bradfordnya yaitu 5,14

Setelah diketahui pengganda bradfordnya, maka persamaan bradfordnya dapat diketahui sebagai berikut

$$
\begin{gathered}
1: \mathrm{n}: \mathrm{n}^{2} \\
1: 5,14: 5,14^{2} \\
1: 5,14: 26,42
\end{gathered}
$$

\section{Verifikasi Hukum Bradford melalui Leimkuhler Model}

Pengujian bradford dilakukan untuk mengetahui kaidah bradford ini diterima pada pengujian produktifitas jurnal Yuridika yang dihitung dalam kurun waktu 3 tahun yaitu tahun 2015-2016. Pengujian ini dibantu dengan menggunakan persamaan Model Leimkuhler. Berikut persamaannya

$$
\mathrm{R}(\mathrm{r})=\mathrm{a} \log (1+\mathrm{br})
$$

Di mana, $\mathrm{R}(\mathrm{r})$ = komulatif artikel yang berkontribusi pada rangking jurnal $1,2,3 \ldots . . r$ 


$$
\begin{aligned}
& \mathrm{a}=\frac{\mathrm{Y} 0}{\log e k} \\
& \mathrm{~b}=\frac{(\mathrm{k}-1)}{r 0}
\end{aligned}
$$

Sebelum masuk pada persamaan Model Leimkuhler, dilakukan perhitungan nilai $\mathrm{Y}_{0}$ melalui persamaan berikut ini:

$$
\mathrm{Y}_{0}=\frac{A}{P}
$$

Keterangan:

$\mathrm{Y}_{0}=$ Nomer artikel di setiap zona bradford

$\mathrm{A}=$ jumlah komulatif artikel, yang diketahui dalam jurnal Yuridika dalam periode 3 tahun (2015-2017) sebanyak 254 artikel

$\mathrm{P}$ = Zona Jurnal (sebanyak 3 zona)

Maka,

$$
\begin{aligned}
Y_{0} & =\frac{254}{3} \\
& =84,67=85
\end{aligned}
$$

Setelah nilai $\mathrm{Y}_{0}$ diketahui, kemudian menghitung nilai a dan $\mathrm{b}$,

$$
\begin{aligned}
\mathrm{a} & =\frac{\mathrm{Y} 0}{\log e k} \\
& =\frac{85}{\log e 4,87}
\end{aligned}
$$




$$
\begin{aligned}
& =\frac{85}{0,69} \\
& =123,19 \\
b & =\frac{(\mathrm{k}-1)}{r 0} \\
\mathrm{~b} & =\frac{(4,87-1)}{4,42} \\
& =0,88
\end{aligned}
$$

Setelah nilai a dan b diketahui, kemudian masuk pada persamaan Model Leimkuhler.

$$
\begin{aligned}
& \qquad \mathrm{R}(\mathrm{r})=\mathrm{a} \log (1+\mathrm{b} \cdot \mathrm{r}) \\
& \mathrm{R}(\mathrm{r})=\mathrm{a} \log \mathrm{e}(1+\mathrm{br}) \\
& =123,19 \log \mathrm{e}(1+0,88 \cdot 7) \\
& =123,19 \log \mathrm{e}(1+6,16) \\
& =123,19 \log \mathrm{e}(7,16) \\
& =123,19 \cdot 0,855 \\
& =105,32=105
\end{aligned}
$$

Dapat dilihat dari perhitungan persamaan di atas, bahwa nilai dari komulatif artikel yang dimuat oleh Jurnal Yuridika tahun 2015-2017 berada pada nilai praduga sebesar 105 dengan menggunakan komulatif jurnal (r) sebesar 7. Apabila dilihat pada tabel 2. nilai komulatif artikel yang terletak pada komulatif jurnal (r) 7 sebesar 106. Hasil tersebut menunjukkan bahwa nilai praduga (105) dan nilai pengamatan (106) tidak jauh berbeda, hanya selisih 1 angka saja, maka dapat disimpulkan bahwa hukum bradford dapat diterima. 
Berikut ini gambar grafiknya

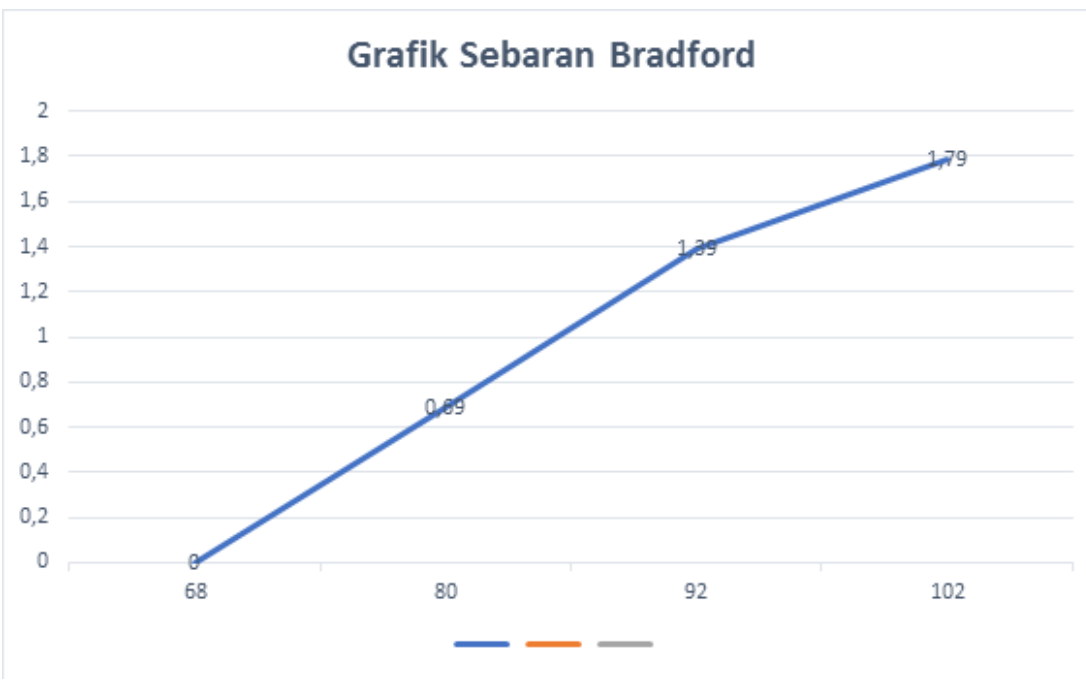

\section{Penutup}

Berdasarkan perhitungan yang telah dilakukan, hasil perhitungan menunjukkan bahwa pola distribusi jurnal Yurdika dalam kurun waktu tiga tahun yaitu 2015-2017 dengan total artikel sebanyak 254 dan terdapat 131 nama jurnal sesuai dengan pola distribusi bradford $1: n: n^{2}$. Pembagian pola distribusi tersebut yaitu sebanyak 4 jurnal mencakup 92 artikel, sebanyak 22 jurnal mencakup 57 artikel, dan sebanyak 105 jurnal mencakup 105 artikel. Ketika model Leimkuhler digunakan untuk verifikasi kaidah Bradford, hasil perhitungan ditemukan bahwa kaidah bradford dinyatakan valid untuk menemukan data set. Studi ini juga menyoroti berbagai langkah-langkah kajian bibliometrik yang dapat digunakan untuk memahami karakteristik dan menyajikan produktivitas dari jurnal yang pada gilirannya mencerminkan karakteristik literatur dan perilaku komunikasi yang dilakukan oleh penulis. Selama periode waktu, Jurnal Yuridika Fakultas Hukum Universitas Airlangga telah muncul sebagai salah satu jurnal penting dan berpengaruh di bidang subjek hukum dan alat komunikasi yang bagus untuk untuk mempublikasikan hasil penelitian. 


\section{Daftar Pustaka}

Banateppanvar, K., Birdar, B. S., \& Kannappanavar, B. U. (2013). Citation analysis of doctoral thesis in botany submitted to Kuvempuuniversity, India a case study. Collection Building, 32(1), 12-20.

Birger, H., \& Jeppe, N. (2005). Bradford's law of scattering: Ambiguities in the concept of "subject".

Cahyono, H. A. (2011). Perilaku pencarian informasi: Studi kasus di Jurusan Syari’ah Sekolah Tinggi Agama Islam Negeri Pamekasan. (Skripsi). Depok: Universitas Indonesia.

Imtihana, O. (2012). Perilaku penemuan informasi di kalangan profesional (Studi deskriptif terhadap Dosen Sejarah di Universitas Airlangga, Universitas Negeri Surabaya dan Universitas Negeri Malang). (Skripsi). Surabaya: Universitas Airlangga.

Jayanti, T. P. (2017). PERILAKU penemuan informasi Dosen Fakultas Hukum Universitas Airlangga Surabaya. (Skripsi). Surabaya: Universitas Airlangga

Jena, K. L., Swain, D. K., \& Sahu, S. B. (2012). Scholarly communication of The Electronic Library from 2003-2009: A bibliometric study. The Electronic Library, 30(1), 103-119.

Mamdapur, G. M. N., Rajgoli, I. U., Chavan, S. M., and Khamitkar, K. S. (2014). Bibliometric Portrait of SRELS Journal of Information Management for the Period 2004-2013. Library Philosophy and Practice, 1166.

Sudhier, K. G. (2010). Application of Bradford's Law of scattering to the physics literature: A study of doctoral theses citations at the Indian Institute of Science. DESIDOC Journal of Library and Information Technology, 30(2), 3-14.

Wardikar, V. G. V. (2013). Application of Bradford's Law of Scattering to the Literature of Library \& Information Science: A Study of Doctoral Theses Citations Submitted to the Universities of Maharashtra, India. Library Philosophy and Practice, 1054.

Zafrunnisha, N. (2012). Citation analysis of PhD Theses in psychology of selected universities in Andhra Pradesh India. Library Philosophy and Practice (E-journal). 